\title{
Cloning, sequencing and disruption of a bromoperoxidase-catalase gene in Streptomyces venezuelae: evidence that it is not required for chlorination in chloramphenicol biosynthesis
}

\author{
Sandra J. Facey, ${ }^{1}$ Frank Groß, ${ }^{1}$ Leo C. Vining, ${ }^{2}$ Keqian Yang $^{2}$ and \\ Karl-Heinz van Pée ${ }^{3}$
}

1 Institut für Mikrobiologie, Universitat Hohenheim, Garbenstraße 30, D-70593 Stuttgart, Germany

2 Department of Biology, Dalhousie University, Halifax, Nova Scotia, Canada B3H 4J1

3 Institut fur Biochemie, Technische Universitat Dresden, Mommsenstraße 4, D-01062 Dresden, Germany Author for correspondence: Karl-Heinz van Pée. Tel: +49351463 4494. Fax: +49351 4635506.
e-mail: chr@ctch02.chm.tu-dresden.de

Genomic DNA libraries of Streptomyces venezuelae ISP5230 and of a mutant blocked at the chlorination step of chloramphenicol biosynthesis were probed by hybridization with a synthetic oligonucleotide corresponding to the $\mathrm{N}$ terminal amino acid sequence of a bromoperoxidase-catalase purified from the wild-type strain. Hybridizing fragments obtained from the two strains were cloned and sequenced. Analysis of the nucleotide sequences demonstrated that the fragments contained the same 1449 bp open reading frame with no differences in nucleotide sequence. The deduced polypeptide encoded 483 amino acids with a calculated $M_{r}$ of 54200 ; the $\mathrm{N}$-terminal sequence was identical to that of the bromoperoxidase-catalase purified from wild-type $S$. venezuelae. Comparison of the amino acid sequence predicted for the cloned bromoperoxidase-catalase gene (bca) with database protein sequences showed a significant similarity to a group of prokaryotic and eukaryotic catalases, but none to other peroxidases or haloperoxidases. Replacement of the bca gene in the wild-type strain of $S$. venezuelae with a copy disrupted by insertion of a DNA fragment encoding apramycin resistance did not prevent chloramphenicol production. The results suggest that the role of the enzyme in S. venezuelae is related to its activity as a catalase rather than as a halogenating agent.

Keywords: Streptomyces venezuelae, bromoperoxidase-catalase, chloramphenicol, gene disruption

\section{INTRODUCTION}

Many micro-organisms produce chlorinated compounds with antibiotic activity (Strunz, 1984), but in only a few has the biochemical mechanism for introducing chlorine been examined in detail. An extensive study of chlorination in the fungus Caldariomyces fumago, which produces caldariomycin through the action of a chloroperoxidase (Morris \& Hager, 1966), led to a general expectation that similar enzymes would prove to be responsible for the

Abbreviation: bca, gene encoding bromoperoxidase-catalase The GenBank accession number for the nucleotide sequence of the wildtype gene reported in this paper is $X 74791$. introduction of chlorine into most natural products (Neidleman \& Geigert, 1986). Streptomyces venezuelae ISP5230 produces the antibiotic chloramphenicol (Vining \& Westlake, 1984), in which two atoms of chlorine are contained within an $\mathrm{N}$-dichloroacetyl substituent. Although incorporation of chlorine during the biosynthesis of chloramphenicol has been attributed to a chloroperoxidase (Neidleman \& Geigert, 1986), only bromoperoxidases have been isolated from this strain (Knoch, 1988). The properties of one such enzyme, designated bromoperoxidase I, are similar to those of a haemcontaining bromoperoxidase found in Streptomyces phaeocbromogenes (van Pée \& Lingens, 1984, 1985), which also produces chloramphenicol. A second halogenating enzyme in $S$. venezuelae resembles bromoperoxidase $I$ in 
containing haem and in being able to brominate but not to chlorinate monochlorodimedone; however, it is distinctly different in having strong catalase but very low peroxidase activity. This bromoperoxidase-catalase $\left(M_{\mathrm{r}} 127000-\right.$ 136000) consists of two identical subunits of apparent $M_{\mathrm{r}}$ 61000 (Knoch et al., 1989). In contrast to other haem haloperoxidases and like typical catalases (Nadler et al., 1986), it shows catalase activity that is $\mathrm{pH}$-independent in the range $\mathrm{pH} 5-10$, is inhibited by 3-amino-1,2,4-triazole, is stable to treatment with a mixture of ethanol/ chloroform and is not inactivated by sodium dithionite (Knoch et al., 1989).

In $S$. venequelae $\mathrm{cml}-2$, a chloramphenicol-nonproducing mutant that forms corynecins (unhalogenated analogues of chloramphenicol) and is presumed to be blocked in the chlorination step of the biosynthetic pathway (Doull et al., 1985), the bromoperoxidase-catalase was inactive (Knoch et al., 1989). Since chloroperoxidases catalyse the oxidation of $\mathrm{Br}^{-}$and $\mathrm{Cl}^{-}$, the concurrent loss of both chlorinating and brominating activity suggested that the $S$. venezuelae bromoperoxidase-catalase would function as a chlorinating enzyme with the appropriate substrate. We report here the cloning and sequencing of the bromoperoxidase-catalase gene ( $b c a$ ) from $S$. venezuelae ISP5230 and show that it is unaltered in the mutant $\mathrm{cml}-2$. By disrupting the gene and introducing the disrupted copy into $S$. venezuelae to replace the native gene, we demonstrated that the bromoperoxidase-catalase is not required for chloramphenicol production.

\section{METHODS}

Bacteria, plasmids and culture conditions. Streptomyces venezuelae ISP5230 (ATCC 10712; Stuttard, 1982) and the mutant cml-2 were maintained on MYM medium as described by Doull et al. (1985). Cultures of Streptomyces lividans TK64 (Hopwood et al., 1983) harbouring recombinant plasmids were grown at $30^{\circ} \mathrm{C}$ in $\mathrm{SM}$ medium $(2 \%, \mathrm{w} / \mathrm{v}$, soybean flour, $2 \%, \mathrm{w} / \mathrm{v}$, mannitol) containing thiostrepton $\left(5 \mu \mathrm{g} \mathrm{ml}^{-1}\right.$ in liquid media, $50 \mu \mathrm{g} \mathrm{ml}^{-1}$ in agar media; thiostrepton was kindly donated by $\mathrm{E}$. R. Squibb and Sons). Cultures of Escherichia coli TG1 (Carter $e t$ al., 1985) and E. coli 12567 (MacNeil et al., 1992) were grown at $37^{\circ} \mathrm{C}$ in LB medium (Sambrook et al., 1989). Enriched genomic libraries were constructed in the high-copy-number plasmid vector pUC18 (Yanisch-Perron et al., 1985). Plasmids pI J486 (Ward et al., 1986) and pHJL400 (Larson \& Hershberger, 1986) were used in subcloning for heterologous expression and gene disruption. Transformants carrying pUC18 and derivative plasmids were selected on agar media containing ampicillin $\left(100 \mu \mathrm{g} \mathrm{ml}^{-1}\right)$, 5-bromo-4-chloro-3-indolyl- $\beta$-D-galactopyranoside (X-Gal; $40 \mu \mathrm{g} \mathrm{ml} \mathrm{m}^{-1}$ ) and $0.2 \mathrm{~mm}$ isopropyl- $\beta$-D-thiogalactopyranoside (IPTG). Recombinant plasmids in $E$.. coli TG1 were identified as white colonies in LB soft agar containing $\mathrm{X}-\mathrm{Gal}$ and IPTG.

Transformation and DNA manipulation. S. lividans TK64 protoplasts were prepared, transformed and regenerated on R2YE agar; transformants were selected by overlaying the agar with $1 \mathrm{ml}$ of a thiostrepton suspension $\left(200 \mu \mathrm{g} \mathrm{ml}^{-1}\right)$ in water (Hopwood et al., 1985). Protoplasts of $S$. venequelae were prepared and transformed as reported by Aidoo et al. (1990). Procedures for transforming $E$. coli and for recovering $E$. coli plasmid and phage DNA were as described by Sambrook et al.
(1989). Genomic DNA was isolated from Streptomyces strains as described by Hopwood et al. (1985). Plasmids were obtained from $S$. lividans transformants by the alkaline lysis procedure of Kieser (1984). DNA fragments were isolated from agarose gels with the Geneclean II kit (Dianova).

$\mathbf{N}$-terminal amino acid sequence and oligonucleotide synthesis. Bromoperoxidase-catalase was isolated from cultures of S. venezuelae ISP5230 as reported previously (Knoch et al., 1989). After further purification by nondenaturing PAGE, the protein was transferred to a polyvinylidine difluoride (Immobilon, Millipore) membrane. The bromoperoxidase-catalase band detected with Coomassie blue was excised and used to determine the $\mathrm{N}$-terminal amino acid sequence of the protein by automated Edman degradation (Applied Biosystems protein sequencer). A 48-mer deoxyinosine-containing oligodeoxynucleotide probe with fourfold degeneracy was synthesized by the Regional DNA Synthesis Laboratory, University of Calgary, Canada (Applied Biosystems 380B DNA synthesizer), purified by gel electrophoresis and end-labelled with digoxigenin-dideoxyuridine triphosphate.

Cloning of the bromoperoxidase-catalase gene. Southern hybridization of $S$. venequelae ISP5230 genomic DNA using the oligodeoxynucleotide probe detected a $2 \cdot 2 \mathrm{~kb}$ hybridizing fragment in BamHI digests. Fragments of about $2 \cdot 2 \mathrm{~kb}$ were extracted from the agarose gel after electrophoresis of a digest, and ligated to pUC18 that had been digested with Bam HI and treated with shrimp alkaline phosphatase (US Biochemical). Transformation of $E$. coli TG1 with the ligation mixture yielded an enriched genomic minilibrary. The library was screened by colony hybridization at $50^{\circ} \mathrm{C}$ with the oligodeoxynucleotide probe (Sambrook et al., 1989). Nylon membranes were washed $(15 \mathrm{~min})$ twice at $50^{\circ} \mathrm{C}$ in $2 \times \mathrm{SSC}$, once at $50^{\circ} \mathrm{C}$ in $1 \times \mathrm{SSC}$, and once at $65^{\circ} \mathrm{C}$ with $1 \times$ SSC. All wash solutions contained $0 \cdot 1 \%$ sodium dodecyl sulphate; $1 \times$ SSC consisted of $150 \mathrm{~mm}$ $\mathrm{NaCl}$ and $15 \mathrm{~mm}$ sodium citrate, $\mathrm{pH} 7 \cdot 0$. Hybridizing DNA fragments were detected with the DIG luminescence detection kit (Boehringer Mannheim).

With the same oligodeoxynucleotide probe, Southern hybridization of genomic DNA from $S$. venezuelae mutant $\mathrm{cml}-2$ digested with $B g / \mathrm{II}$ and Pst detected $b c a$ in a $3.5 \mathrm{~kb}$ fragment. Fragments about $3.5 \mathrm{~kb}$ in size were retrieved from the digest and ligated to pUC18 linearized with Bam $\mathrm{HI}$ and Pst I to generate an enriched genomic minilibrary in E. coli as above. The $3.5 \mathrm{~kb}$ fragment was detected by colony hybridization and isolated by the procedures described.

Sequence determination and analysis. DNA fragments were cloned in M13mp18 or M13mp19 (Yanisch-Perron et al., 1985), and sequenced using a T7 sequencing kit (Pharmacia) by the chain-termination method of Sanger et al. (1977). Nucleotide sequences were analysed with the GENMON program (Gesellschaft für Biotechnologische Forschung, Braunschweig, FRG); they were compared with the EMBL nucleotide sequence data library. Amino acid sequences were compared with the SWISSPROT protein database. The CLUSTAL program for multiple sequence alignment was kindly provided by the German Cancer Research Center, Heidelberg, in the software package HUSAR.

Construction of replacement vectors. The Streptomyces-E. coli bifunctional vector pHJL400 (Larson \& Hershberger, 1986), which is segregationally unstable in $S$. venezuelae, was modified to obtain the replacement vectors pDQ402 and pDQ403 by inserting in both orientations a DNA fragment carrying bca disrupted at its $S a l$ site with a gene conferring apramycin resistance $\left(\mathrm{Apr}^{\mathbf{R}}\right)$. To construct the insert, pSF2201 was linearized by digestion with $X b a \mathrm{I}$ and $P s t \mathrm{I}$, and the single-strand 
overhangs were filled by incubation with the Klenow fragment and deoxynucleotide triphosphates. Ligation of the blunt ends yielded pDQ401, in which the Sall site of the pUC18 multiple cloning sequence in pSF2201 had been deleted. A DNA fragment conferring $\mathrm{Apr}^{\mathrm{R}}$ was then inserted within the bca sequence in pDQ401. The fragment conferring $\mathrm{Apr}^{\mathbf{R}}$ was obtained from pKC462a (Stanzak et al., 1986). A $1.5 \mathrm{~kb}$ BamHI-PstI fragment carrying the gene was excised and cloned in pBluescriptII $\mathrm{SK}(+)$, from which it was then retrieved as a BamHI-HindIII fragment. This was end-filled by Klenow treatment, and ligated to pDQ401, which had been linearized at its unique $S a l I$ site (within $b c a$ ) and also end-filled by Klenow treatment. The plasmids extracted from E. coli TG1 transformants were digested with $\mathrm{Bam} \mathrm{HI}$ to yield $3.7 \mathrm{~kb}$ fragments in which the DNA (in its two orientations) conferring $\mathrm{Apr}^{\mathrm{R}}$ was flanked by $S$. venezuelae DNA. One such fragment was recloned in each orientation in the $\mathrm{BamHI}$ site of $\mathrm{pHJL} 400$ to give the replacement vectors $\mathrm{pDQ} 402$ and $\mathrm{pDQ} 403$.

Protein electrophoresis, enzyme assays and protein measurements. For native enzymes, $7 \cdot 5 \%$ (w/v) polyacrylamide gels $(\mathrm{pH} 7 \cdot 5)$ were used (Maurer, 1964). Brominating activity was detected by the conversion of phenol red to bromophenol blue as described by Knoch et al. (1989). Gels were stained for proteins with Coomassie blue R250. Catalase activity was measured spectrophotometrically at $240 \mathrm{~nm}$ (Beers \& Sizer, 1952) with $6.5 \mathrm{mM} \mathrm{H}_{2} \mathrm{O}_{2}$ (in $100 \mathrm{~mm}$ sodium acetate buffer, $\mathrm{pH}$ $5.5)$ as the substrate. One unit of catalase converted $1 \mu \mathrm{mol}$ $\mathrm{H}_{2} \mathrm{O}_{2}$ to $\mathrm{H}_{2} \mathrm{O}$ in $1 \mathrm{~min}$ at $25^{\circ} \mathrm{C}$. Protein was determined by the Lowry method, using a bovine serum albumin standard.

\section{Partial purification of bromoperoxidase-catalase expressed} from cloned bca. The enzyme was kept at $4{ }^{\circ} \mathrm{C}$ throughout the purification. Solutions were buffered with sodium acetate at $\mathrm{pH}$ 5.5 . The $2.2 \mathrm{~kb} \mathrm{BamHI}$ insert of pSF2201 was recloned in BamHI-digested and dephosphorylated pIJ486; the recombinant vector was used to transform S. lividans TK64 protoplasts. Transformants grown at $30^{\circ} \mathrm{C}$ for $6 \mathrm{~d}$ in $100 \mathrm{ml} \mathrm{SM}$ medium supplemented with thiostrepton were harvested by centrifugation, resuspended in twice their volume of $100 \mathrm{~mm}$ buffer and disrupted by sonication for $20 \mathrm{~min}$ (Branson Sonifier 450, $160 \mathrm{~W}, 50 \%$ duty cycle). The supernatant obtained by centrifugation $(22100 \mathrm{~g}, 30 \mathrm{~min})$ of the sonicate was dialysed against $100 \mathrm{~mm}$ buffer for $15 \mathrm{~h}$, clarified by centrifugation as before, and applied to a DEAE cellulose column (Whatman DE52, 5.5 X $11 \mathrm{~cm}$ ) equilibrated with $150 \mathrm{~mm}$ buffer. Proteins were eluted with a gradient $(600 \mathrm{ml})$ of $150-700 \mathrm{~mm}$ buffer. Fractions $(4 \mathrm{ml})$ with at least $25 \%$ of the catalase activity of the most active fraction were pooled and concentrated by ultrafiltration (Amicon PM-30 membrane).

Measurement of chloramphenicol production. Cultures were incubated in $250 \mathrm{ml}$ Erlenmeyer flasks on a rotary shaker $(220$ r.p.m.) at $27^{\circ} \mathrm{C}$. For chloramphenicol production, portions $(25 \mathrm{ml})$ of glucose-isoleucine medium (Doull et al., 1985) were inoculated $(4 \%, \mathrm{v} / \mathrm{v})$ from a vegetative culture prepared by incubating $S$. venezuelae spores for $24 \mathrm{~h}$ in $10 \mathrm{ml} \mathrm{GNY}$ medium (Malik \& Vining, 1970). The chloramphenicol production cultures were examined after $3 \mathrm{~d}$ growth by extracting a $3 \mathrm{ml}$ sample of the clarified broth with an equal volume of ethyl acetate. The extract, after evaporation, was taken up in $0.1 \mathrm{ml}$ methanol/water $(3: 1)$, and a sample $(20 \mu \mathrm{l})$ was analysed by high-performance liquid chromatography (HPLC) using a $\mathrm{C}_{\mathbf{1 8}}$ reverse-phase column $(80 \times 4.0 \mathrm{~mm})$ and stepped linear gradients from 0 to $25 \%(\mathrm{v} / \mathrm{v})(1 \mathrm{~min}), 25$ to $50 \%(5 \mathrm{~min})$ and 50 to $100 \%$ (1 min) of methanol/water, followed by $100 \%$ methanol for $1 \mathrm{~min}$, and a gradient returning to $100 \%$ water $(1 \mathrm{~min})$. Chloramphenicol was eluted at $6.05 \mathrm{~min}$; its concentration was estimated by comparing the peak area with peak areas given by reference samples.

\section{RESULTS}

\section{Isolation of bca from S. venezuelae ISP5230}

Edman analysis of the bromoperoxidase-catalase purified from $S$. venezuelae ISP5230 identified 27 amino acids in the N-terminal sequence (Fig. 1a). This information was used to synthesize a 48-mer oligonucleotide corresponding to amino acids 2-17. Degeneracy was minimized by taking account of the biased codon usage in streptomycetes (Wright \& Bibb, 1992). To further reduce the complexity of the mixed probe population, deoxyinosines were used at seven ambiguous positions where the codon usage bias was insufficient (see Fig. 1a). Probing a Bam HI digest of genomic DNA from $S$. venezuelae ISP5230 with the oligonucleotide detected a $2 \cdot 2 \mathrm{~kb}$ hybridizing fragment. This fragment was isolated as a Bam HI insert (Fig 1b) in pSF2201 by screening an enriched minilibrary of $S$. venequelae genomic DNA in pUC18. A colony of $E$. coli TG1 containing pSF2201 was identified by hybridization with the oligodeoxynucleotide probe.

(a)

\section{Peptide sequence}

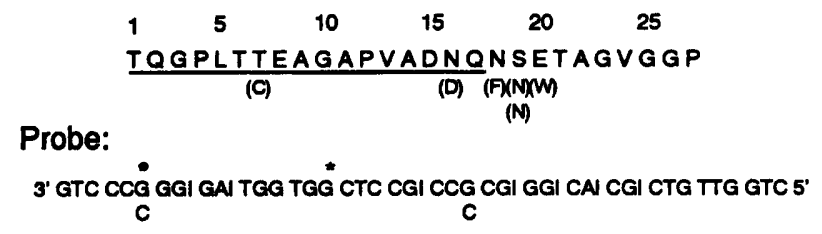

(b)

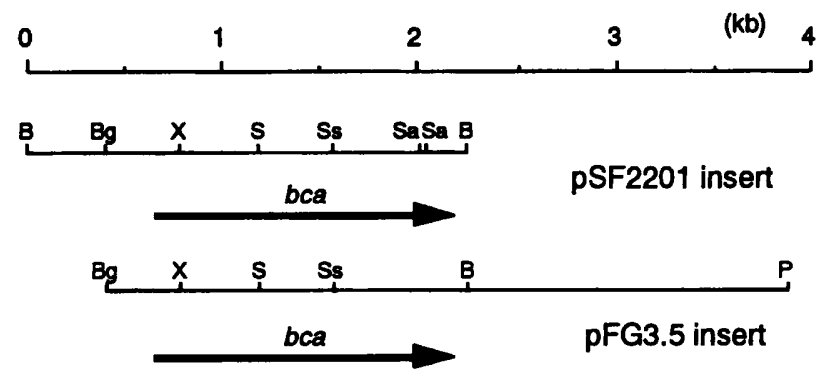

Fig. 1. (a) Sequence of amino acids at the $\mathrm{N}$-terminus of the bromoperoxidase-catalase of S. venezuelae ISP5230, determined by the Edman procedure. The synthetic oligodeoxynucleotide probe (shown below) based on the sequence of amino acids 2-17 contained deoxyinosine (l) at positions where codon degeneracy prevented preferential assignments. Asterisks indicate nucleotides that did not match the bca sequence determined later. (b) Restriction maps of the fragments of $S$. venezuelae chromosomal DNA cloned in pSF2201 from the wild-type strain (ISP5230), and in pFG3.5 from the chlorinationdeficient mutant (cml-2). Only restriction sites used for sequence analysis are shown. The arrows locate bca as determined from the nucleotide sequence: $B, B a m H I, B g, B g / I$; P, Pstl; X, Xhol; S, Sall; Ss, Sstl; Sa, Sau3A1. 
5'-

GGATCCTATAGATCCGGGCCCTGATCGCGTTTCCGGACGCAACCGGACGCACCCCGGGCGCAACAGTAAAGCCCCCGCCG CGGCGGGGGCTTCTGTGTGGGCGTCTCAGGCGCTGCCGGCGCAGCTGGGGCAGATGCCTCGGTAGGTGACCTCGACGTTC 80 GAGATGGTGAAGCCGAAGCGCTCGGTGTCCGGCAGGTCGGCCAGCGGGTCGCCGCCCGGATGCACATCGCGGATCGCGCC GCAGCGGCCGCAGACCAGGTGCTGGTGCGGCCGGTGGGCGTTGGGGTCGTAGCGCTTGGCGCGGCCGTCGGTCGCGACCT CGATGACCTCGCCGAGGGTGACCATCTCGCCGAGCGTGTTGTAGACGGTCGCGCGCGAGATCTCGGGCAGGCGCGTCACG 320 GCGCGCGCGTGGACCTCGTCGGCGGTCAGGTGTACGTGGTCCCCGTCCAGGACCTCCGCCACCACACGCCGCTGCGCGGT 400 CATCCGCCAGCCGCGTCCGCGCAGTCGTTCCAACAGGTCACTCATGAGGGCCAGCCTAACAGTCGGGGGCGCCGCTTCCC 480 GAACCGGTGTGACTTTGGATGTTCACPTGACTYTAGACATTGTCTATCGTAGGATCGAGTACGGCACGCAGGACAGGACGC AGGAGGCGCACGTGACGCAGGGACCGCTCACCACGGAGGCCGGCGCGCCGGTCGCCGACAACCAGAACAGCGAGACGGCG $\begin{array}{llllllllllllllllllllllllllll}G & V & G & G & P & V & L & V & Q & D & Q & L & L & L & E & K & L & A & H & E & N & R & E & R & I & P & E\end{array}$ GGCGTAGGCGGTCCGGTCCTCGTCCAGGACCAGCTGCTGCTCGAGAAGCTCGCCCACTTCAACCGTGAGCGCATCCCGGA GCGCGTGGTCCACGCGCGCGGTGCGGGCGCCTACGGCACCTTCACGCTCACCCGTGACGTCTCGCGGTGGACGCGGGCCG $\begin{array}{lllllllllllllllllllllllllllll}A & F & L & S & E & V & G & K & R & T & E & T & F & L & R & F & S & T & V & A & G & S & L & G & A & A & D\end{array}$ $\begin{array}{lllllllllllllllllllllllllll}A & V & R & D & P & R & G & W & A & L & K & F & Y & T & E & E & G & N & Y & D & L & V & G & N & N & T & P\end{array}$ GCGGTGCGCGATCCGCGCGGCTGGGCGCTGAAGTTCTACACCGAGGAGGGCAACTACGACCTCGTCGGCAACAACACCCC $\begin{array}{lllllllllllllllllllllllllll}V & F & F & I & K & D & A & I & K & F & P & D & F & I & H & T & Q & K & R & D & P & Y & T & G & S & Q\end{array}$ GGTGTTCTTCATCAAGGACGCCATCAAGTTCCCCGACTTCATCCACACCCAGAAGCGCGACCCGTACACGGGCTCGCAGG AGGCGGACAACGTCTGGGACTTCTGGGGCCTGTCGCCGGAGTCGACCCACCAGGTGACCTGGCTGTTCGGCGACCGCGGC ATCCCGGCCTCGTACCGCCACATGAACGGCTACGGCTCGCACACGTACCAGTGGACCAACGAGGCCGGCGAGGTCTTCTG

1200 CCTCTACGACGGCCGCCACAAGGGCGCGAAGAACTACGAGCCCAACTCCTTCGGCGGACCGGTCCAGACGGACCGCCCGC 
30

40

50

60

bca_strve catv bacsu cata_bovi cata_human

bca_strve catv_bacsu cata- mouse cata-moune

bcastrve catv bacsu cata bovin cata mouse cata human

bca_strve catv bacs catabovin cata mous cata_human

bca_strve catv_bacsu cata_bovin cata mouse cata_human

bea_strve catv_bacsu cata_bovin cata mouse cata human

bca_strve catv bacsu cata_bovin cata mouse cata_human

bca_strve cat v_bacsu cata_bovin cata_mouse cata_human

MTQGP - ....... LTTEAGAPVADNQNSETAGVGGPVLVQDQLLLEK MSSNK -.............. - LTTSWGAPVGDNONSMTAGSRGPTLIODVHLLEK -ADNRDPASDQMKHWKEQRAAQKPDVLTTGGGNPVGDKLNSLTVGPRGPLIVQDVVFTDE MSDSRDPASDQMKQWKEORASORPDVLTTGGGNPIGDKLNIMTAGSRGPLLVQDVVFTDE MADSRDPASDQMOHWKEORAAQKADVLTTGAGNPVGDKLNVITVGPRGPLLVQDVVFTDE 1

LAHFNRERIPERY TIARGAGAYGTFTLTRDVSRWTRAAFLSEVGKRTETFLRFSAR/AGSL LAHFNRERVPERY FAKGAGAHGYFEVTNDVTKYTKAAFLSEVGKRTPLFIRFS N VAGEL MAHFDPER I PERU JAKGAGAFGYFEVTHDITRYSKAKVFEHIGKRTPIAVRF TAGES MAHFDRERIPERY HAKGAGAFGYFEVTHDITRYSKAKVFEHIGKRTPIAVR F MATF MARF RERI

GAADAVRDPRGWALKFYTEEGNYDLVGNNTPYFIKDAII PDPIHTQKRDPYTGSQEAD GSATR GSADTVDPRGFAVKFTEDGNWLVANTP FFIRDALY PSFIHSQKRNPQTHLKDPD VITH

NVWDFWGLSPESTHQVTWLFGDRGI PASYRHMNGYGSHTYQWNNEAGEVFWVKYHFKTDO AVWDFWSLSPESLHOVTILMSDRGI PATLRHMHGFGSHTFKWTNAEPEGVWI KYHFKTEO MUTD MUUDFSLRPESLHQVSTLTSDRGIDGHRI MVWDFWLRPESLHQVSFLFSDRGIPDGHRHMNGYGSHTFKLVNANGEAVYCKFHYXTD

GIKNLTODEANRLAGEDPDSHORDLREAIERGDFPTWTVQVQIMPAADAAGYRFNPFDLT GVKNLDVNTAAK IAGENPDYHTEDLFNAIENGDY GIKNLSVEDAARLAHEDPDYGLRDLFNAI ENGDY FAWKLYVQIMPLEDA YIOVMTFSEAEIFPFNPFDL GIKNLSVEDAARLSQEDPDYG IRDLFNAIATGKYPSWTFYIQVMTFNQAETFPFNPFDLT *** *...*** ** ${ }^{* * *} * * * * * * * * *$

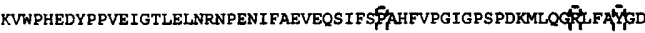
KVWSQKDYPLIEVGRMVLDRNPENYFAEVEQATFSEGTLVPGIDVS PDKMLQCRR FAMHD

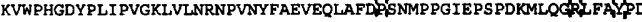
KVWPHKDYPLI PVGKLVL NXNPVNYFAEVEOMAFDPSNMPPGIEPS PDKMLOGE FPAPD KVWPHKDYPLIPVGKLVLNRNPVNYFAEVEOIAFDPGNMPPGIEASPDKMLOG FAYPD $* * * \ldots * * * * * * * * * * * * * * * * * * * * * * *$

AHRYRVG INADHLPVNRP - HATEARTHSRDGFLYDGRHKGAKNYEPNSFGGPVOTDRPL AHRYRVGANHOALPINRA-RNKYNNYORDGOMTFDDNGGGSVYYBPNSFGGPKESPEDKO THRHRLONYQIPVICPYRA VAN Thro THRHRLGPNYLH I PVNCPYRARVANYQRDGPMCMQDNQGGAPNYYPNSFGAPEQQPSAL

QPTPVTGVTGDHAAPSHAEDDDFTQAGDLY-RLMSEDEKGRLIDNLSGFIAKVSRDDIAE

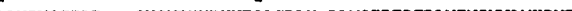
ARPV W H HS IQ - - YSGEVRR NIANDDNVTQVRAFYVNVLNEEQRKRLCENIAGHLKD-AQIFIQ

RAIGNFRRADEDFGKRLEAAVQ - ................ALR- -G(2) KAVKNFTDVHPDYGARIOALLDKYNAEKRKNAIHTYTOAGSHMAAKGKANL KAVKNFTEVHPDYGSHIQALLDKYNAEKPKNAIHTFVQSGSHLAAREKANL $* * \ldots *$ ********* GAADAVRDPRGWALKFYTEEGNYLVGNTPY FIKDAI FDFIHTQKRDPYTGSQEAD GSADTVRDPRGFAVKFYTEDGNWDLVGNNTP LFIRDPILESFIHSQKRNPQTHLKDPD GIKNLPVGEAGRLAQEDPDYGLRDLFNAIANGNYPSWTFYIQVMTFKEAETFPFNPFDL

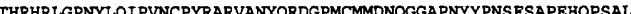
RQIEHFYKADPEYGKRVAEGLG-

Fig. 3. Alignment of the bromoperoxidase-catalase from $S$. venezuelae (bca_strve) with Bacillus subtilis vegetative catalase (catv_bacsu), bovine liver catalase (cata_bovin), mouse catalase (cata_mouse) and human catalase (cata_human). Asterisks identify amino acids common to all five proteins. Similar amino acids are marked by dots. Hyphens indicate gaps introduced to increase similarity. Arrows indicate amino acids in the active centre. Amino acids on the distal side of the haem-binding site are enclosed with solid lines, those on the proximal side with dashed lines. Parameters for CLUSTAL pairwise similarity scores are: K-tuple length $=1$, gap penalty $=3$, window size $=5$, multiple alignment gap penalty $=10$

\section{Nucleotide sequence and sequence analysis of bca}

The DNA sequence of the insert in pSF2201 (Fig. 2) and a codon usage analysis of the sequence established that an open reading frame (ORF) was present (see Fig. 1b). The $\mathrm{G}+\mathrm{C}$ content of the $1449 \mathrm{bp} \mathrm{ORF}$ was $70 \mathrm{~mol} \%$, and the frequency of codons containing $\mathrm{G}$ or $\mathrm{C}$ in the third position was $97.5 \%$. These values are consistent with the high percentage of $\mathrm{G}+\mathrm{C}$ in the genomic DNA of streptomycetes (Enquist \& Bradley, 1971; Wright \& $\mathrm{Bibb}, 1992$ ). The sequence at the $5^{\prime}$-end is close (only two of the 48 bases are mismatched) to that of the mixed synthetic oligonucleotide probe used for hybridization (see Fig. 1a). The translational initiation codon at nt 652-654 is GTG, which in the G+C-rich DNA of streptomycetes is not uncommon as a start codon. Five base pairs upstream from this GTG is a putative Shine-Dalgarno sequence (SD; Shine \& Dalgarno, 1974) for ribosome binding [5'-AGGAGG-3', $\Delta G-9 \cdot 4 \mathrm{kcal}$ $\mathrm{mol}^{-1}\left(39 \cdot 3 \mathrm{~kJ} \mathrm{~mol}^{-1}\right)$; Tinoco et al., 1973] that matches the consensus SD for S. lividans (Bibb \& Cohen, 1982). A potential promoter sequence comprising -35 ( $5^{\prime}$ TTGACT-3'; nt 587-592) and - 10 (5'-TAGGAT-3'; nt 609-614) hexamers separated by $16 \mathrm{bp}$ is located upstream of the initiation codon. The -35 hexamer shows $5 / 6$ homology with the consensus -35 sequences of both $E$. coli and E. coli-like Streptomyces promoters (Strohl, 1992); in the -10 region, the homology with the consensus sequences for E. coli and E. coli-like Streptomyces promoters is $4 / 6$ and $6 / 6$, respectively. An imperfect inverted repeat sequence (nt 2122-2141 and 2142-2161) representing a putative termination signal is present $18 \mathrm{bp}$ downstream of the TGA termination codon at nt 2101-2103.

\section{Characteristics of the deduced amino acid sequence}

The ORF encodes a $54 \mathrm{kDa}$ polypeptide with 483 amino acids. The deduced amino acid sequence at the $\mathrm{N}$-terminus precisely matches that of the purified bromoperoxidasecatalase determined by Edman degradation. In a search of protein databases (SWISS-PROT, EMBL), no appreciable sequence similarity was found between the predicted ORF product and known haloperoxidases. However, significant similarity was found to several catalases (Fig. 3 ), notably Bacillus subtilis vegetative catalase $(59 \cdot 2 \%$ identity; Bol \& Yasbin, 1991), mouse catalase $(51.3 \%$ identity; Shaffer et al., 1990), bovine liver catalase (51.3\% identity; Schroeder et al., 1982) and human kidney catalase (50.9\% identity; Bell et al., 1986). The three amino acids (His-74, Ser-113 and Asn-147) participating in the active site of bovine liver catalase (Fita \& Rossmann, 1985) are conserved in the $S$. venequelae bromoperoxidase-catalase as His-54, Ser-93 and Asn-127 (see Fig. 3). Furthermore, the four amino acids (Val-73, Thr-114, Phe-152 and Phe-160) interacting with the distal side of the haem group of bovine liver enzyme, and the three (Pro-335, Arg-353 and Tyr-357) interacting on the proximal side, have counterparts (Val-53, Thr-94, Phe-132, Phe-140, Pro-315, Arg333 and Tyr-337, respectively), in the bromoperoxidasecatalase sequence.

\section{Expression of the cloned S. venezuelae bca in S. lividans}

To confirm that the DNA insert cloned in pSF2201 encodes the bromoperoxidase-catalase purified from $S$. venezuelae, the Bam $\mathrm{HI}$ fragment was excised and recloned in pI J486. The recombinant plasmid (pSF2202) was used to transform the heterologous host S. lividans TK64. Extracts of the transformant, as well as of S. lividans TK64(pI J486), were examined for haloperoxidase activity. As this activity usually cannot be detected in crude 
1

2

3
2

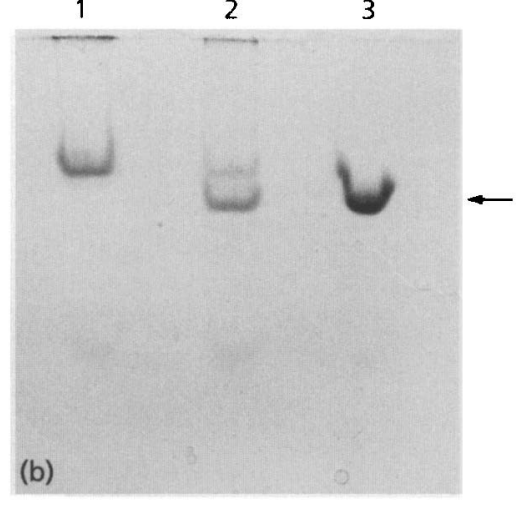

Fig. 4. Polyacrylamide gel electrophoresis of partially purified bromoperoxidase-catalase from S. venezuelae and S. lividans under nondenaturing conditions. (a) Gel stained for brominating activity with phenol red. (b) Gel stained for protein with Coomassie blue. Lanes: 1, protein $(35 \mu \mathrm{g})$ from $S$. lividans TK64(plJ486) after ion-exchange chromatography; 2 , protein $(35 \mu \mathrm{g})$ from S. lividans TK64(pSF2202) after ion-exchange chromatography; 3, bromoperoxidase-catalase $(15 \mu \mathrm{g})$ from S. venezuelae ISP5230 after hydrophobic-interaction chromatography. The position of the bromoperoxidase-catalase is indicated by an arrow. extracts of streptomycete mycelium (van Pée, 1988), the extracts were partially purified to remove inhibiting substances before electrophoresis on a nondenaturing polyacrylamide gel. Staining with phenol red showed two blue bands due to brominating activity in S. lividans TK64(pI J486), whereas the pSF2202 transformant gave three blue bands (Fig. 4). The third band coincided with that obtained with partially purified bromoperoxidasecatalase from $S$. venezuelae ISP5230. Protein staining of the gel visualized a band in the S. lividans TK64(pSF2202) extract that also matched the band in the $S$. venequelae ISP5230 extract, but was absent from the extract of $S$. lividans TK64(pI J486).

\section{Isolation and nucleotide sequence of bca from mutant cml-2}

Probing a $B g / \mathrm{II} /$ PstI digest of genomic DNA from $S$. venezuelae $\mathrm{cml}-2$ with the synthetic oligodeoxynucleotide shown in Fig. 1(a) detected a 3.5 kb hybridizing fragment. The fragment was obtained in pFG3.5 by screening an enriched genomic minilibrary of $S$. venezuelae $\mathrm{cml}-2$ DNA in pUC18, using the colony hybridization procedure described earlier for isolating pSF2201. The inserts cloned in pFG3.5 and pSF2201 were shown to be in the same region of chromosomal DNA by restriction mapping (see Fig 1b). Sequencing demonstrated that the insert contained a 1449 bp ORF identical in all respects to $b c a$ cloned in pSF2201 from the wild-type $S$. venequelae.

\section{Disruption of the bromoperoxidase-catalase gene}

A replacement vector was prepared by inserting the $A \mathrm{pr}^{\mathrm{R}}$ gene from pKC462a (Stanzak et al., 1986) into the SalI site internal to the $b c a$ insert in pDQ401 (pSF2201 modified by deleting Sall from the multiple cloning site). The disrupted $b c a$ construct was recloned in both orientations in the BamHI site of the shuttle vector pHJL400 to give pDQ402 and pDQ403 (Fig. 5a). To reduce the severity of the apparent restriction barrier against methylated DNA in S. venezuelae (Han et al., 1994), replacement vectors were isolated from the E. coli dam dcm hsdM strain ET12567 (MacNeil et al., 1992). With this DNA, S. venezuelae gave (per $\mu \mathrm{g}$ of the vector used) approximately $100 \mathrm{Apr}^{\mathrm{R}} \mathrm{Thio}^{\mathrm{R}}$ transformants. Two of these (VS661 and VS662), with the
Bam HI insert in opposite orientations, were examined. Southern hybridization with $\mathrm{pDQ} 402$ as the probe indicated that the plasmid had integrated into the chromosome of each strain by single homologous recombination. The integrants were propagated on thiostrepton-free medium for two generations to allow vector excision and elimination (Paradkar et al., 1993); progeny screened for loss of thiostrepton resistance yielded strains with an $\mathrm{Apr}^{\mathbf{R}} \mathrm{Thio}^{\mathrm{S}}$ phenotype. Southern hybridization using pDQ402 to probe chromosomal DNA from these strains (e.g. VS663 derived from VS661, and VS664 derived from VS662; Fig. 5b) indicated that the vector DNA had been excised by a second crossover, resulting in replacement of the native $b c a$ with the disrupted copy from pDQ402 or pDQ403, respectively.

Measurement of chloramphenicol production by the strains in which $b c a$ had been modified by either vector integration or gene replacement gave titres of $60-75 \mu \mathrm{g}$ $\mathrm{ml}^{-1}$, within the range of wild-type values under the growth conditions used. The product was indistinguishable from authentic chloramphenicol when co-chromatographed by HPLC, and differed in retention time from reference samples of corynecins. The results indicated that the intact bromoperoxidase-catalase gene is not required for the chlorination reaction in chloramphenicol biosynthesis.

\section{DISCUSSION}

The close similarity between the oligodeoxynucleotide probe sequence and $5^{\prime}$ sequences of the ORFs within the fragments cloned from S. venezuelae ISP5230 and its $\mathrm{cml}-2$ mutant indicate that the gene for the bromoperoxidasecatalase isolated from the wild-type strain by Knoch et al. (1989) was correctly targeted by the synthetic oligonucleotide. This is supported by the complete identity of the $\mathrm{N}$-terminal amino acid sequence deduced for the cloned gene with the N-terminal amino acid sequence obtained from the purified bromoperoxidase-catalase. Further evidence is provided by the detection of an $S$. venequelae-like bromoperoxidase-catalase in S. lividans tranformants carrying the cloned gene from $S$. venequelae ISP5230. The two bands of brominating activity detected after electrophoresis of an extract of S. lividans transformed 
(a)

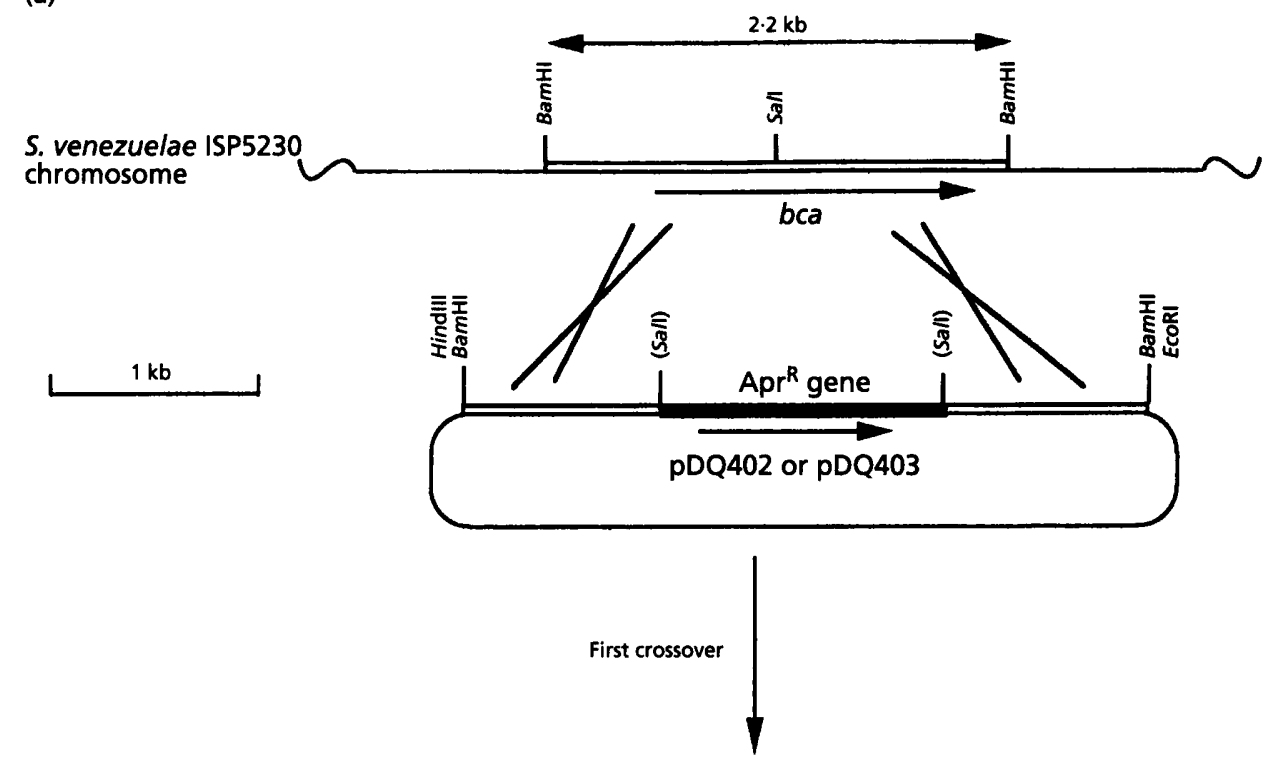

VS661 or VS662 (Thio ${ }^{R}$ Apr $^{R}$ ) (b)

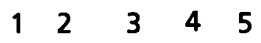

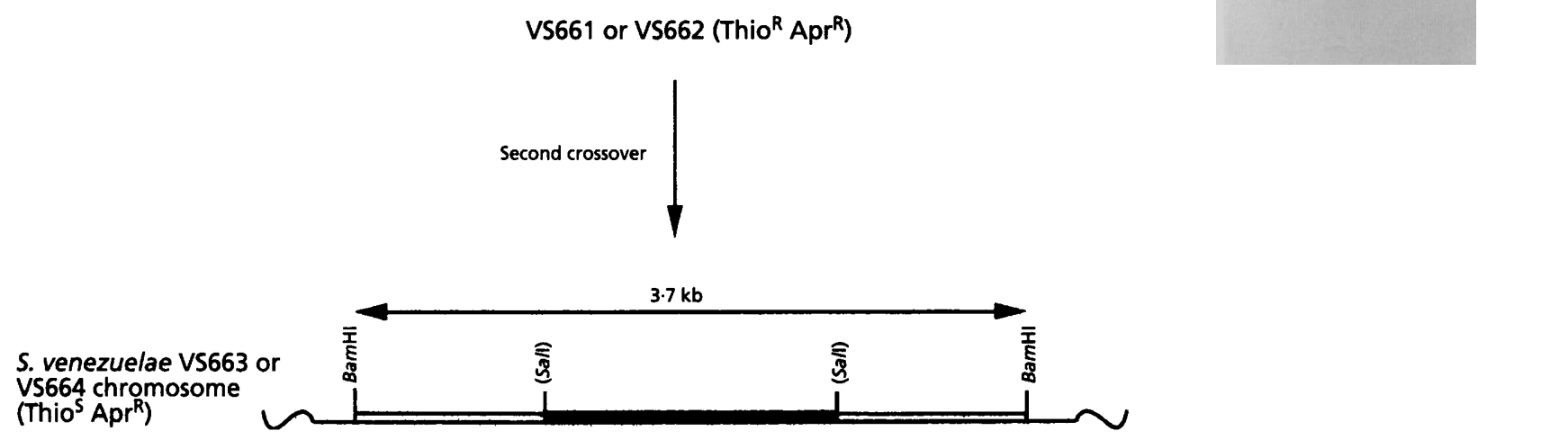

Fig. 5. Disruption and replacement of bca in S. venezuelae. (a) Transformation of S. venezuelae ISP5230 with the replacement vectors pDQ402 and pDQ403, and selection for both Thio ${ }^{R}$ and Apr ${ }^{R}$ gave VS661 and VS662. Propagation of these transformants without thiostrepton selection and screening for Thio Apr $^{R}$ progeny yielded VS663 and VS664. (b) Southern hybridization using pDQ402 to probe $S$. venezuelae chromosomal DNA digested with BamHI and electrophoresed in a $0.7 \%$ agarose gel. Lanes: 1, VS663; 2, VS664; 3, VS661; 4, VS662; 5, ISP5230. The relatively high intensity of the hybridizing bands at 3.7 and $5.8 \mathrm{~kb}$ is due to integration of multiple copies of the plasmid vector into the chromosome of single-crossover strains VS661 and VS662, as observed previously in S. venezuelae ISP5230 (Paradkar et al., 1993; Han et al., 1994).

with the vector alone are consistent with earlier results indicating that $S$. lividans contains at least one non-haem haloperoxidase (van Pée, 1988; Bantleon et al., 1994). As far as we know, S. lividans TK64 harbouring pIJ486 does not produce any halogenated metabolites, and thus the role of these enzymes is not clear.

Since $b c a$ is intact in the cml-2 mutant of $S$. venezuelae, the absence of the chlorinated metabolite from cultures, and of halogenating activity in the protein corresponding to the bromoperoxidase-catalase in fractionated cell extracts from cml-2 (Knoch et al., 1989), are clearly not caused by a mutation within $b c a$. The $\mathrm{cml}-2$ mutation may affect an ancillary reaction needed to generate an active enzyme; if so, the same reaction is presumably involved not only in introducing chlorine into chloramphenicol, but also in the activity of other halogenating enzymes, such as the bromoperoxidase-catalase reported here. It may be significant that the $M_{\mathrm{r}}$ of 54200 calculated for the product of $b c a$ is below the expected size for a dimeric protein in a native enzyme determined by gel filtration to have an $M_{\mathrm{r}}$ of 127000-136000 (Knoch et al., 1989). The ability of strains in which bca had been replaced by a disrupted gene to continue making chloramphenicol confirms that $b c a$ is not essential for biosynthesis of the antibiotic.

The coding sequence of the $S$. venezuelae gene is preceded by a plausible SD sequence and by a promoter-like structure resembling the consensus promoter sequences of $E$. coli genes and $E$. coli-like Streptomyces genes recognized by the vegetative $E \sigma^{70}$-type RNA polymerase holoenzyme. Since genes associated with either primary or secondary metabolism in streptomycetes can be transcriptionally controlled by such promoters (Baltz, 1990; 
Strohl, 1992), a role for $b c a$ in primary metabolism cannot be inferred from this information. Of interest, however, is the close similarity reported recently between the amino acid sequence of the $S$. venezuelae bromoperoxidasecatalase and the sequences of several peptides from the single catalase in Streptomyces coelicolor A3(2) (Walker et al., 1995). This enzyme and the major catalase in a second $S$. coelicolor strain (Kim et al., 1994) are potentially involved in the response to oxidative stress. Both are tetrameric proteins with subunits of $M_{\mathrm{r}} 55000 \pm 2000$ (Kim et al., 1994; Walker et al., 1995). In this they resemble the catalase of Haemophilus infuenzae (Bishai et al., 1994), and for the $S$. coelicolor A3(2) protein the resemblance extends to the amino acid sequence (Walker et al., 1995).

The amino acid sequence deduced for the $S$. venezuelae bromoperoxidase-catalase has strong similarity to that of the oxygen-responsive catalase in the anaerobe Bacteroides fragilis (Rocha \& Smith, 1995). The two proteins belong to a group of dimeric catalases with subunit sizes of approximately $55000 \mathrm{Da}$; the group includes the catalases from Mycobacterium tuberculosis (Dias \& Wayne, 1974), Comamonas compransoris (Nies \& Schlegel, 1982) and Klebsiella pneumoniae (Goldberg \& Hochman, 1989). It shares sequence similarity with the tetrameric catalases of similar subunit size, and with a number of other catalases from Gram-positive and Gram-negative bacteria (Rocha \& Smith, 1995). The evolutionary relationship indicated by sequence similarities between the $S$. venequelae bromoperoxidase-catalase and catalases from animals as well as bacteria, and the functional relationship implied by the conservation of amino acids established from the crystal structure of bovine liver catalase to be structurally and catalytically important residues (Fita \& Rossmann, 1985), suggest that the catalase activity of the bromoperoxidasecatalase may determine the role of this enzyme in $S$. venezuelae.

\section{ACKNOWLEDGEMENTS}

We thank D. Kliemt for technical assistance. We also thank $\mathrm{K}$. Jouvenal and Dr F. Tripier from Hoechst AG, Frankfurt, and Dr H. Brückner and $\mathrm{H}$. Kieß from the Institut für Lebensmitteltechnologie, Universität Hohenheim, for determining the partial amino acid sequence. The work was supported by the Deutsche Forschungsgemeinschaft (DFG) and the Natural Sciences and Engineering Research Council (NSERC) of Canada.

\section{REFERENCES}

Aidoo, D. A., Barrett, K. \& Vining, L. C. (1990). Plasmid transformation of Streptomyces venezuelae: modified procedures used to introduce the gene(s) for $p$-aminobenzoate synthase. J Gen Microbiol $136,657-662$.

Baltz, R. H. (1990). Gene expression using streptomycetes. Curr Opinion Biotechnol 1, 1-12.

Bantleon, R., Altenbuchner, J. \& van Pée, K.-H. (1994). Chloroperoxidase from Streptomyces lividans: isolation and characterization of the enzyme and the corresponding gene. J Bacteriol 176, 2339-2347.

Beers, R. F. \& Sizer, I. W. (1952). A spectrophotometric method for measuring the breakdown of hydrogen peroxide by catalase. $J$ Biol Chem 195, 133-140.

Bell, G. I., Najarian, R. C., Mullenbach, G. T. \& Hallewell, R. A. (1986). cDNA sequence coding for human kidney catalase. Nucleic Acids Res 14, 5561-5562.

Bibb, M. J. \& Cohen, S. N. (1982). Gene expression in Streptomyces: construction and application of promoter-probe plasmid vectors in Streptomyces lividans. Mol \& Gen Genet 187, 265-277.

Bishai, W. R., Smith, H. O. \& Barcak, G. J. (1994). A peroxide/ ascorbate-inducible catalase from Haemophilus influenzae is homologous to the Escherichia coli katE gene product. J Bacteriol 176, 2914-2921.

Bol, D. K. \& Yasbin, R. E. (1991). The isolation, cloning and identification of a vegetative catalase gene from Bacillus subtilis. Gene 109, 31-37.

Carter, P., Bedouelle, H. \& Winter, G. (1985). Improved oligonucleotide site-directed mutagenesis using M13 vectors. Nucleic Acids Res 13, 4431-4443.

Dias, G. A. \& Wayne, L. G. (1974). Isolation and characterization of catalase produced by M. tuberculosis. Annu Rev Respir Dis 110, 312-319.

Doull, J. L., Ahmed, Z., Stuttard, C. \& Vining, L. C. (1985). Isolation and characterization of Streptomyces venezuelae mutants blocked in chloramphenicol biosynthesis. J Gen Microbiol 131, 97-104.

Enquist, L. W. \& Bradley, S. G. (1971). Characterization of deoxyribonucleic acid from Streptomyces venezuelae spores. Dev Ind Microbiol 12, 225-236.

Fita, I. \& Rossmann, M. G. (1985). The active center of catalase. $J$ Mol Biol 185, 21-37.

Goldberg, I. \& Hochman, A. (1989). Purification of a novel type of catalase from the bacterium Klebsiella pneumoniae. Biochim Biophys Acta 991, 330-336.

Han, L., Yang, K., Ramalingam, E., Mosher, R. H. \& Vining, L. C. (1994). Cloning and characterization of polyketide synthase genes for jadomycin B biosynthesis in Streptomyces venezuelae ISP5230. Microbiology 140, 3379-3389.

Hopwood, D. A., Kieser, T., Wright, H. M. \& Bibb, M. J. (1983). Plasmids, recombination and chromosome mapping in Streptomyces lividans 66. J Gen Microbiol 129, 2257-2269.

Hopwood, D. A., Bibb, M. J., Chater, K. F., Kieser, T., Bruton, C. J., Kieser, H. M., Lydiate, D. J., Smith, C. P., Ward, J. M. \& Schrempf, H. (1985). Genetic Manipulation of Streptomyces: a Laboratory Manual. Norwich: John Innes Foundation.

Kieser, T. (1984). Factors affecting the isolation of ccc DNA from Streptomyces lividans and Escherichia coli. Plasmid 12, 19-36.

Kim, H., Lee, J. S., Hah, Y. C. \& Roe, J. H. (1994). Characterization of the major catalase from Streptomyces coelicolor ATCC 10147. Microbiology 140, 3391-3397.

Knoch, M. (1988). Haloperoxidasen aus einem Chloramphenicol-produzierenden Streptomyces venequelae-Stamm und einer nichtproduqierenden Mutante. Dissertation, Institut für Mikrobiologie, Universität Hohenheim, Germany.

Knoch, M., van Pée, K.-H., Vining, L. C. \& Lingens, F. (1989). Purification, properties and immunological detection of a bromoperoxidase-catalase from Streptomyces venezuelae and from a chloramphenciol-nonproducing mutant. J Gen Microbiol 135, 2493-2502.

Larson, J. L. \& Hershberger, C. L. (1986). The minimal replicon of a streptomycete plasmid produces an ultrahigh level of plasmid DNA. Plasmid 15, 199-209.

MacNeil, D. J., Gewain, K. M., Ruby, C. L., Dezeny, G., Gibbons, P. H. \& MacNeil, T. (1992). Analysis of Streptomyces avermitilis genes 
required for avermectin biosynthesis utilizing a novel integration vector. Gene 111, 61-68.

Malik, V. S. \& Vining, L. C. (1970). Metabolism of chloramphenicol by the producing organism. Can J Microbiol 16, 173-179.

Maurer, H. R. (1964). Disk-Elektrophorese: Theorie and Praxis der diskontinuierlichen Polyacrylamidgelelektrophorese. Berlin: Walter de Gruyter.

Morris, D. R. \& Hager, L. P. (1966). Chloroperoxidase I. Isolation and properties of the crystalline glycoprotein. J Biol Chem 241, 1763-1768.

Nadler, V., Goldberg, I. \& Hochman, A. (1986). Comparative study of bacterial catalases. Biocbim Biophys Acta 882, 234-241.

Neidleman, S. L. \& Geigert, J. (1986). Biobalogenation: Principles, Basic Roles and Applications. Chichester: Ellis Horwood.

Nies, D. \& Schlegel, H. G. (1982). Catalase from Comamonas compransoris. J Gen Appl Microbiol 28, 311-319.

Paradkar, A. S., Stuttard, C. \& Vining, L. C. (1993). Location of the genes for anthranilate synthase in Streptomyces venezuelae ISP5230: genetic mapping after integration of the cloned genes. $J$ Gen Microbiol 139, 687-694.

van Pée, K.-H. (1988). Molecular cloning and high-level expression of a bromoperoxidase gene from Streptomyces aureofaciens Tü24. $J$ Bacteriol 170, 5890-5894.

van Pée, K.-H. \& Lingens, F. (1984). Detection of a bromoperoxidase in Streptomyces phaeochromogenes. FEBS Lett 173, 5-8.

van Pée, K.-H. \& Lingens, F. (1985). Purification and molecular and catalytic properties of bromoperoxidase from Streptomyces phaeocbromogenes. J Gen Microbiol 131, 1911-1916.

Rocha, E. R. \& Smith, C. J. (1995). Biochemical and genetic analyses of a catalase from the anaerobic bacterium Bacteroides fragilis. $J$ Bacteriol 177, 3111-3119.

Sambrook, J., Fritsch, E. F. \& Maniatis, T. (1989). Molecular Cloning: a Laboratory Manual, 2nd edn. Cold Spring Harbor, NY: Cold Spring Harbor Laboratory.

Sanger, F., Nicklen, S. \& Coulson, A. R. (1977). DNA sequencing with chain-terminating inhibitors. Proc Natl Acad Sci USA 74, 5463-5467.

Schroeder, W. A., Shelton, J. R., Shelton, J. B., Robberson, B., Apell, G., Fang, R. S. \& Bonaventura, J. (1982). The complete amino acid sequence of bovine liver catalase and the partial sequence of bovine erythrocyte catalase. Arch Biochem Biopbys 214, $397-421$.

Shaffer, J. B., Preston, K. E. \& Shepard, B. A. (1990). Nucleotide and deduced amino acid sequences of mouse catalase: molecular analysis of a low activity mutant. Nucleic Acids Res 18, 4941.

Shine, J. \& Dalgarno, L. (1974). The $3^{\prime}$-terminal sequence of Escherichia coli $16 \mathrm{~S}$ ribosomal RNA: complementarity to nonsense triplets and ribosome binding sites. Proc Natl Acad Sci USA 71, 1342-1346.

Stanzak, R., Matushima, P., Baltz, R. H. \& Rao, R. N. (1986). Cloning and expression in Streptomyces lividans of clustered erythromycin biosynthesis genes from Streptomyces erythreus. Bio/Technology 4, 229-232.

Strohl, W. R. (1992). Compilation and analysis of DNA sequences associated with apparent streptomycete promoters. Nucleic Acids Res 20, 961-974.

Strunz, G. M. (1984). Microbial chlorine-containing metabolites. In Handbook of Microbiology, 2nd edn, vol. 5, Microbial Products, pp. 749-773. Edited by A. I. Laskin \& H. A. Lechevalier. Boca Raton, FL: CRC Press.

Stuttard, C. (1982). Temperate phages of Streptomyces venequelae: lysogeny and host specificity shown by phages SV1 and SV2.J Gen Microbiol 128, 115-121.

Tinoco, I., Jr, Borer, P. N., Dengler, B., Levine, M. D., Uhlenbeck, O. C., Crothers, D. M. \& Gralla, J. (1973). Improved estimation of secondary structure in ribonucleic acids. Nature New Biol 246, 40-41.

Vining, L. C. \& Westlake, D. W. S. (1984). Chloramphenicol: properties, biosynthesis and fermentation. In Biotechnology of Industrial Antibiotics, pp. 387-411. Edited by E. J. Vandamme. New York: Marcel Dekker.

Walker, G. E., Dunbar, B., Hunter, I. S., Nimmo, H. G. \& Coggins, J. R. (1995). A catalase from Streptomyces coelicolor A3(2). Microbiology 141, 1377-1383.

Ward, J. M., Janssen, G. R., Kieser, T., Bibb, M. J., Buttner, M. J. \& Bibb, M. J. (1986). Construction and characterisation of a series of multi-copy promoter-probe plasmid vectors for Streptomyces using the aminoglycoside phosphotransferase gene from $\operatorname{Tn} 5$ as indicator. Mol \& Gen Genet 203, 468-478.

Wright, F. \& Bibb, M. J. (1992). Codon usage in the G+C-rich Streptomyces genome. Gene 113, 55-65.

Yanisch-Perron, C., Vieira, J. \& Messing, J. (1985). Improved M13 phage cloning vectors and host strains: nucleotide sequences of the M13mp18 and pUC19 vectors. Gene 33, 103-109.

Received 8 August 1995; revised 10 November 1995; accepted 20 November 1995. 